\title{
A New Clue in the Mystery of Neuro-AIDS
}

Elyse J. Singer, $M D$

\section{HIV Infection Causes Neurologic Disease}

The HIV (HIV) causes AIDS (AIDS). HIV/AIDS currently infects over 40 million people worldwide. AIDS is a major cause of neurologic disease, in addition to its betterknown complications of serious infections and tumors.

\section{Dementia Most Common AIDS-Related Neurologic Disease}

The most common AIDS-related brain disorder is called HIVassociated dementia complex (HAD). The major symptoms of HAD are gradually progressive problems with memory, concentration, and thinking (also called cognitive impairment), that can lead to dementia.

\section{Immune System Problems May Lead to Brain Damage}

Luo and colleagues (Neurology 2003) address the theory that HAD is associated with the presence of an infection-fighting white blood cell called a monocyte-derived macrophage (MDM). The MDM is part of the body's immune system. These cells are made in the bone marrow and released into the blood. In HIV-infected patients, the MDMs behave abnormally and cause damage to the organs they pass through. When these MDMs enter the brain, they release toxic substances. Over time, these toxins cause brain cell damage and death. This results in the clinical symptoms of HAD. Abnormally behaving MDMs may also lead to neurologic symptoms in patients without HIV infection.

The investigators collected blood from three groups of women who had similar age, education, language, and ethnic background: (1) healthy HIV-negative women; (2) HIV-infected women without cognitive impairment; and (3) HIVinfected women with cognitive impairment. They separated out the MDMs from each patient's blood and used a number of new techniques (collectively called proteomic analyses) to detect and measure the amounts of proteins made by MDM. The investigators found a unique profile of proteins that was associated with HIV infection and with cognitive impairment.

Patients with HIV infection may have to undergo time-consuming, expensive, and uncomfortable tests to determine if their symptoms are caused by HAD. In addition, there are no tests that predict which HIV patients are at risk for developing HAD. This research may lead to a
Major Symptoms in HAD

\begin{tabular}{ll}
\hline Cognitive & \multicolumn{1}{c}{ Motor } \\
\hline Memory & $\begin{array}{l}\text { Weakness, } \\
\text { Incoordination, } \\
\text { Loss, } \\
\text { Decreased }\end{array}$ \\
$\begin{array}{l}\text { Attention/ } \\
\text { Concentration }\end{array}$ & movements \\
\hline Behavioral & \multicolumn{1}{c}{ Mood } \\
\hline Apathy/Social & Depression, \\
Isolation, & Personality \\
Loss of drive, & change, \\
Irritability, & Intense \\
Poor Judgment & excitability \\
\hline
\end{tabular}

fast, non-invasive test to diagnose HAD earlier and to follow the response of HAD patients to therapy. It may also lead to a test to predict which HIV-infected persons are at risk for HAD.

This work highlights an important interaction between the immune system and the brain. The MDM when affected by a viral infectionlike HIV can be triggered to migrate into the brain, causing damage there. Other diseases that affect the immune system could trigger abnormal MDMs as well. If so, this could also be an important cause of neurologic and psychiatric disease in people without HIV. 


\section{What is HAD?}

The most common AIDS-related brain disorder is called HIVassociated dementia complex (HAD). Dementia is a brain disorder that affects a person's ability to think clearly and even makes performing daily activities difficult. Patients with HAD have problems in four areas of function: (1) ability to understand, process, and remember information (cognitive functions); (2) behavioral changes; (3) motor problems; and (4) mood changes (see Table). Currently, up to $15 \%$ of adults with AIDS develop $\mathrm{HAD}$, even if they are given appropriate treatment for AIDS. HAD occurs more commonly and is more severe in children with HIV than in adults.

\section{What Causes HAD?}

We do not know for sure how HIV causes HAD. HIV does not directly infect nerve cells, however, HIV can injure and kill them indirectly. Macrophages, white blood cells that live in the brain, are infected with HIV. These cells enter the brain from the bloodstream and are the largest reservoir of HIV in the brain. The macrophage releases a number of substances that can be toxic to nerve cells, leading to brain damage and the symptoms of HAD. It is also possible that cells in the brain other than nerve cells can be infected with HIV and lead to nerve cell damage.

\section{How Is HAD Diagnosed?}

HAD can be difficult to diagnose in its early stages because the first symptoms are similar to those of many other disorders, such as thyroid disease, drug abuse, depression, and other brain infections. The main way to detect and evaluate a patient with HAD is through a mental status exam. This is an examination performed by a physician that evaluates memory and concentration functions and mood. Brain imaging is also performed, mainly to look for causes of dementia other than HAD. A spinal tap is also usually performed to look for other causes of dementia. Although some patients with HAD have higher levels of certain proteins, white blood cells, and HIV in their spinal fluid, not all patients with these findings have or develop HAD. It is also helpful to assess the patient's stage of HIV disease because people with very high levels of CD4 cells (main cells that are infected and destroyed by HIV) rarely get HAD.

\section{How Is HAD Treated?}

The best therapies to treat HAD seem to be anti-HIV drugs. Usually combinations of drugs are needed. Drugs are selected that we know get into the brain in high concentration. Several research studies have shown that the use of this type of anti-HIV drug combination can lead to improvement of HAD or even prevent HIV infection of the brain. Many therapies are also available to treat specific symptoms of HAD, such as mood or behavioral disorders.

\section{Other Sources of Patient Education on This Topic}

AIDS Education Global Information System (AEGIS). Available at: http://www.aegis.com.

National Institute of Neurological Disorders and Stroke Neurological Manifestations of AIDS Information Page. Available at: http://www.ninds.nih.gov/health_and_ medical/disorders/aids.htm.

Neurologic AIDS Research Consortium. Available at: http://www.neuro.wustl.edu/narc. 


\title{
Neurology
}

\author{
A New Clue in the Mystery of Neuro-AIDS \\ Elyse J. Singer \\ Neurology 2003;60;E12-E13 \\ DOI 10.1212/01.WNL.0000072987.37660.7F
}

This information is current as of June 24, 2003

\section{Updated Information \&}

Services

Permissions \& Licensing

Reprints including high resolution figures, can be found at:

http://n.neurology.org/content/60/12/E12.full

Information about reproducing this article in parts (figures,tables) or in its entirety can be found online at:

http://www.neurology.org/about/about_the_journal\#permissions

Information about ordering reprints can be found online:

http://n.neurology.org/subscribers/advertise

Neurology ${ }^{\circledR}$ is the official journal of the American Academy of Neurology. Published continuously since 1951, it is now a weekly with 48 issues per year. Copyright. All rights reserved. Print ISSN: 0028-3878. Online ISSN: 1526-632X.

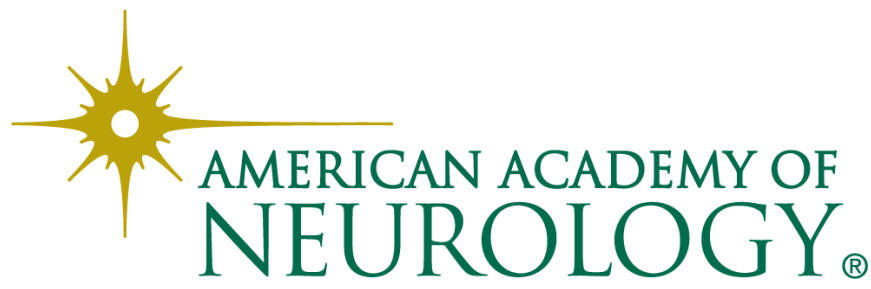

